http://www.jfas.info

\title{
PREVALENCE OF IRON DEFICIENCY AND ITS ASSOCIATED RISK FACTORS AMONG PRIMARY SCHOOL CHILDREN IN KELANTAN
}

\author{
H. Halib ${ }^{1, *}$, W. M. W. Muda ${ }^{2}$, P. C. Dam ${ }^{3}$ and H. J. J. Mohamed ${ }^{2}$
}

\begin{abstract}
${ }^{1}$ Dietetics Programme, School of Health Sciences, Universiti Sultan Zainal Abidin, 21300 Kuala Terengganu, Terengganu, Malaysia

${ }^{2}$ Nutrition Programme, School of Health Sciences, Universiti Sains Malaysia, 16150 Kubang Kerian, Kelantan, Malaysia

${ }^{3}$ Biomedicine Programme, School of Health Sciences, Universiti Sains Malaysia, 16150 Kubang Kerian, Kelantan, Malaysia
\end{abstract}

Published online: 08 August 2017

\begin{abstract}
Iron deficiency anemia (IDA) is the most common micronutrient deficiency that may leads to serious health problems such as poor behavior, cognitive and motor development in children. The main objective of the study was to investigate prevalence of IDA and its associated risk factors of school children. A cross-sectional study was conducted on 249 Malay primary school children (122 males and 127 females), aged 7-9 years old. Venous blood sample was drawn for hemoglobin and serum ferritin analysis. Results revealed that the prevalence of iron deficiency without anemia was $12.6 \%$ and $7.7 \%$ of the children was found to have iron deficiency anemia. Result showed that birth weight, household size, height, weight and BMI was correlated significantly with iron deficiency based on serum ferritin concentration.
\end{abstract}

Keywords: iron deficiency anemia; school children; hemoglobin; serum ferritin analysis.

Author Correspondence, e-mail: hasmizahalib@unisza.edu.my

doi: http://dx.doi.org/10.4314/jfas.v9i2s.27 


\section{INTRODUCTION}

Iron deficiency is a major nutritional deficiency and continues to be an important public health problem in both industrialized countries and developing countries including Malaysia [1]. The prevalence of anemia in developing countries is said to be three to four times higher than that in industrialized countries. In 2002, the World Health Organization (WHO) estimated anemia due to iron deficiency was one of the ten most important factors contributing to the global burden of disease which increases morbidity and mortality in children and pregnant women [2]. WHO also estimated that about two billion people are anemic, and about $50 \%$ are due to iron deficiency [3].

Several studies have shown serious consequences of anemia including impaired cognitive performance [4], behavioral disturbances [5], lower immunity to infections leading to increased risk of mortality and morbidity [6] and also pregnancy complication e.g. low birth weight babies [7]. It also has deleterious effects on school academic performance [8], decline in reproductive performance, physical performance as well as work capacity in adults [9-10]. According to Administrative committee on coordination/Subcommittee on Nutrition (ACC/SCN) [9], pregnant women, pre-schoolchildren and young children aged 5-14 years were identified to be a group of high-risk for IDA due to their high iron requirements. Prevalence of IDA was reported to be as high as 50\% among East Asian school children and $60 \%$ among children less than 5 years of age [11]. Even in developed countries such as the United States, iron deficiency anemia has the highest prevalence among women and young children [12].

Malaysia is one of the developing countries where iron deficiency has been reported to be one of the most important micronutrient deficiencies in the country [13]. Moreover, several studies on IDA in Malaysia also highlighted the problem of IDA among infants, children, adolescent and pregnant women [14-15]. A study conducted in Malaysia demonstrated high prevalence of anemia and IDA among aboriginal schoolchildren aged 7-12 years with almost $49 \%$ of the children were anemic and $70 \%$ of the anemic cases are due to iron deficiency [16]. High prevalence of anemia where it is reported that $54.9 \%$ of the children aged 7-12 years had iron deficiency and $16.9 \%$ had iron deficiency anemia [17]. 
In Malaysia, iron deficiency anemia has been reported as one of the most important micronutrient deficiencies for the past several decades. This study is important as data on iron deficiency anemia among school children is limited, especially in Malaysia where most of the studies often focus on pregnant women and very young children. However, it is crucial to know the iron status of the school children and its associated risk factors as it is known that IDA may lead to poor mental and educational performances.

\section{RESULTS AND DISCUSSION}

\subsection{General Characteristics of the Children}

The study involving 269 children, where all of them are from Malay ethnic group with a proportion of $48.5 \%(n=127)$ male and $51.5 \%(n=135)$ are female. Age of the children ranged from 6 to 10 years with mean \pm SD of $8.01 \pm 0.9$ years. Table 1 show the average of household income was around RM1000/month. The average household size was 6.96 person with almost half of them living in medium household sizes comprising 5 to 8 members per household. Regarding household income per kapita, almost three quarter (77.7\%) of them were categorized as poor and hard core poor. Results showed that $10.6 \%$ of them were born with a low birth weight $(<2.5 \mathrm{~kg})$ and majority of them about $96.8 \%$ were breastfed with $87.2 \%$ were breastfed up to more than 6 months (Table 1).

Table 1. General characteristics of the subjects

\begin{tabular}{ccc}
\hline Factors & $\mathbf{n}$ & $\mathbf{\%}$ \\
\hline Gender & 127 & \\
Male & 135 & 48.5 \\
Female & $(8.01 \pm 0.9)$ & 51.5 \\
Age & 49 & \\
$6.00-6.99$ & 68 & 19 \\
$7.00-7.99$ & 91 & 26.4 \\
$8.00-8.99$ & 50 & 35.3 \\
$9.00-9.99$ & $(1033 \pm 1316)$ & 19.4 \\
\hline
\end{tabular}




\begin{tabular}{|c|c|c|c|c|}
\hline$<500$ & \multicolumn{2}{|c|}{142} & \multicolumn{2}{|c|}{55.5} \\
\hline $501-1000$ & \multicolumn{2}{|c|}{67} & \multicolumn{2}{|c|}{26.2} \\
\hline $1001-1500$ & \multicolumn{2}{|c|}{8} & \multicolumn{2}{|c|}{3.1} \\
\hline$>1500$ & \multicolumn{2}{|c|}{39} & \multicolumn{2}{|c|}{15.2} \\
\hline Household size & \multicolumn{4}{|c|}{$(6.96 \pm 1.97)$} \\
\hline Medium(5-8) & \multicolumn{2}{|c|}{20} & \multicolumn{2}{|c|}{7.7} \\
\hline Large $(>8)$ & \multicolumn{2}{|c|}{187} & \multicolumn{2}{|c|}{71.9} \\
\hline & \multicolumn{2}{|c|}{53} & \multicolumn{2}{|c|}{20.2} \\
\hline Number of children & \multicolumn{4}{|c|}{$(5.18 \pm 2.37)$} \\
\hline $1-3$ & \multicolumn{2}{|c|}{61} & \multicolumn{2}{|c|}{23.3} \\
\hline $4-6$ & \multicolumn{2}{|c|}{100} & \multicolumn{2}{|c|}{38.2} \\
\hline$>6$ & \multicolumn{2}{|c|}{101} & \multicolumn{2}{|c|}{38.5} \\
\hline \multicolumn{5}{|l|}{ Marital status } \\
\hline Married & \multicolumn{2}{|c|}{250} & \multicolumn{2}{|c|}{95.4} \\
\hline Divorced & \multicolumn{2}{|c|}{7} & \multicolumn{2}{|c|}{2.7} \\
\hline Single & \multicolumn{2}{|c|}{5} & \multicolumn{2}{|c|}{1.9} \\
\hline Breast feeding duration (months) & \multicolumn{2}{|c|}{$19.69 \pm 9.03$} & & \\
\hline$<6$ months & \multicolumn{2}{|c|}{30} & \multicolumn{2}{|c|}{12.8} \\
\hline$\geq 6$ months & \multicolumn{2}{|c|}{204} & & \\
\hline Birth weight & $(3.04$ & 49) & & \\
\hline Low birth weight & & & & \\
\hline Normal birth weight & & & & \\
\hline & & & & \\
\hline Occupation & $\mathrm{n}$ & $\%$ & $\mathrm{n}$ & $\%$ \\
\hline Government sector & 32 & 12.3 & 38 & 14.8 \\
\hline Private sector & 4 & 1.5 & 18 & 7 \\
\hline Self-employed & 7 & 2.7 & 31 & 12.1 \\
\hline Others/housewives & 217 & 82.7 & 169 & 66 \\
\hline
\end{tabular}

Results in Table 2 showed mean z-score values for height-for-age, weight-for-age and 
BMI-for-age were $-1.03 \pm 0.88,-0.88 \pm 1.31$ and $15.56 \pm 2.81$ respectively with no significant difference was found between boys and girls. Results for BMI-for-age indicated that $5.6 \%$ and $6.9 \%$ of the children were overweight and obese. In general, data on weight and height (Table 2) of school children in this study indicated that malnutrition is still prevalent among these rural school children. Findings from this study also reported that more male children were found to have higher prevalence of stunting, underweight, thinness as well as overweight and obese compared to female. Boys were more likely to suffer from under nutrition than girls are likely due to the increase nutritional needs in boys than girls [18]. Overweight and obese reflecting over nutrition does co-exist with under nutrition in these subjects. The co-existence of both under nutrition and over nutrition in this study could be due to the interrelating factors such as food intake, socio economic status as well as family dynamics.

Table 2. General characteristics of the subjects

\begin{tabular}{cccc}
\hline $\begin{array}{c}\text { Anthropometric } \\
\text { Parameter }\end{array}$ & Boys Mean (SD) & Girls Mean (SD) & Total Mean (SD) \\
& $\mathbf{N}=\mathbf{1 1 7}$ & $\mathbf{N}=\mathbf{1 1 6}$ & $\mathbf{N}=\mathbf{2 3 3}$ \\
\hline Height $(\mathrm{m})$ & $1.21(0.07)$ & $1.21(0.06)$ & $1.21(0.07)$ \\
Body weight $(\mathrm{kg})$ & $23.19(6.78)$ & $22.82(5.74)$ & $23.01(6.28)$ \\
Body mass index $\left(\mathrm{kgm}^{2}\right)$ & $15.63(3.07)$ & $15.48(2.53)$ & $15.56(2.81)$ \\
Height-for-age & $-1.0670(091)$ & $-0.966(0.84)$ & $-1.0319(0.88)$ \\
Weight-for-age & $-0.9378(1.47)$ & $-0.8567(1.13)$ & $-0.8784(1.31)$ \\
BMI-for-age & $-0.5001(1.45)$ & $-0.4151(1.19)$ & $-0.4678(1.33)$ \\
\hline
\end{tabular}

\subsection{Prevalence of Iron Deficiency and its Associated Risk Factors}

It is estimated that most of the children and pregnant women in developing and developed countries are suffering iron deficiency [19]. Finding from the present study demonstrated that $12.6 \%(26 / 207)$ of the children had ID and 7.7\% (16/207) had IDA (Table 3). Higher rates were reported in other local studies. Study done by [17] among rural children in West Malaysia reported the prevalence of ID and IDA was $54.9 \%$ and $16.9 \%$ respectively. When compare to data from other countries, present study demonstrated a relatively higher prevalence of ID and IDA as compared to countries such as Brazil and South Africa [20-21]. Iron deficiency appeared to be the dominant cause of anemia where more than half $(60 \%)$ of the anemic children in this study had iron deficiency (Table 3). 
Table 3. Status of iron among the children

\begin{tabular}{|c|c|c|c|c|c|c|c|}
\hline \multirow[t]{2}{*}{ Gender } & \multicolumn{3}{|c|}{ Status of Iron } & \multirow{2}{*}{$\begin{array}{c}\text { Hemoglobin } \\
\text { Concentratio } \\
\text { n (g/dL) }\end{array}$} & \multirow{2}{*}{$\begin{array}{c}\text { No. of } \\
\text { Deficient } \\
\text { n(\%) }\end{array}$} & \multirow{2}{*}{$\begin{array}{c}\text { Serum } \\
\text { Ferritin } \\
\text { Concentration }\end{array}$} & \multirow{2}{*}{$\begin{array}{c}\text { No. of } \\
\text { Deficien } \\
\text { t n(\%) }\end{array}$} \\
\hline & $\begin{array}{c}\text { Normal } \\
\text { n (\%) }\end{array}$ & $\begin{array}{c}\text { ID } \\
\text { n (\%) }\end{array}$ & $\begin{array}{c}\text { IDA } \\
\text { n (\%) }\end{array}$ & & & & \\
\hline Boys & 8 & 15 & 8 & $12.69 \pm 0.81$ & 8 & $37.69 \pm 2.83$ & 23 \\
\hline$(n=104)$ & (77.9) & (14.4) & (7.7) & & $(7.7)$ & & $(22.1)$ \\
\hline Girls & 84 & 11 & 8 & $12.87 \pm 1.14$ & 8 & $36.87 \pm 20.68$ & 19 \\
\hline$(n=103)$ & (81.6) & (10.7) & $(7.8)$ & & $(7.8)$ & & (18.4) \\
\hline Total & 165 & 26 & 16 & $12.78 \pm 0.97$ & 16 & $37.28 \pm 21.74$ & 42 \\
\hline$(n=207)$ & (79.7) & (12.6) & (7.7) & & (7.7) & & $(20.3)$ \\
\hline
\end{tabular}

This finding was inconsistent with the results from other studies which have also reported that iron deficiency accounted for almost half of the cases of anemia in Malaysia [17, 22-23]. In contrast, study conducted among 427 school children in Thailand has reported a high prevalence of anemia (19.4\%) with a relatively low prevalence of IDA (4.1\%) suggesting that IDA may not be the most common causes of anemia in this area and could be attributed to thalassemia traits as screening test showed that two-thirds of the children were positive for thalassemia traits [24]. However, present study had screened and excluded those who suspected to have thalassemia trait, STH infection and anemia of other causes which have not further investigated in this study.

Boys had higher percentage of iron deficient compared to girls with $22.1 \%$ and $18.4 \%$ respectively. Total of children who had deficient for hemoglobin $(\mathrm{Hb}<11.5 \mathrm{~g} / \mathrm{dL})$ and ferritin (SF $<15 \mu \mathrm{g} / \mathrm{L}$ ) concentration was $7.7 \%$ and $20.3 \%$ respectively. Independent sample T-test shows no significant difference $(p>0.05)$ was observed in the mean concentration for both hemoglobin and serum ferritin between boys and girls. Result on t-test showed no significant difference in the mean for hemoglobin and serum ferritin between boys and girls. The present findings are in general agreements with other studies, which have also reported that no significant difference was found between females and males children [22]. On top of that, the level of $\mathrm{Hb}$ and serum ferritin of the children aged of 1 year until 10 years old was also found to be constant for both boys and girls [25]. However, findings from other studies among rural 
children and adolescent demonstrated female subjects have significantly lower iron status than the male counterparts [15]. This is due to the physiological iron losses during menstrual bleeding and thus it increased the body iron needs among females adolescent [23]. As for present study, it only involved children aged 7-9 years old and none of our subjects had menarche, therefore no significant differences was found for both mean for hemoglobin and serum ferritin between boys and girls. Besides, in [26] have reported that in pre-pubertal humans, no major differences can be found between the sexes in red blood cells count or hemoglobin and serum ferritin concentration. The difference emerges only after the onset of menstruation. Menstruation is the main cause of iron losses in women and it is considered as normal to find a lower iron status value in women compared to men at this point of time [27].

Result in Table 4 indicates the correlation between family and child characteristics with iron status. Result showed that birth weight, household size, height for age, weight for age and BMI for age was correlated significantly with serum ferritin concentration. The result implied that children who were born with higher birth weight will have higher serum ferritin concentration. Children who had a lower household size also had a better iron status.

Table 4. Correlation between birth weight, father's and mother's education, household income, household size, breastfeeding duration, weight-for-age, height-for-age and BMI for age $\mathrm{z}$ score with haemoglobin and serum ferritin concentration

\begin{tabular}{ccc}
\hline Characteristics & $\begin{array}{c}\text { Haemoglobin } \\
\text { Conc }(\mathbf{g} / \mathbf{d L})\end{array}$ & $\begin{array}{c}\text { Serum Ferritin } \\
\text { Conc }(\mathbf{n g} / \mathbf{m L})\end{array}$ \\
\hline Age & $\mathrm{r}=0.203, \mathrm{p}<0.05$ & $\mathrm{r}=0.037, \mathrm{p}=0.593$ \\
Birth weight $(\mathrm{kg})$ & $\mathrm{r}=0.079, \mathrm{p}=0.294$ & $\mathrm{r}=0.162, \mathrm{p}=0.030$ \\
Father's education (y) & $\mathrm{r}=0.050, \mathrm{p}=0.487$ & $\mathrm{r}=0.113, \mathrm{p}=0.114$ \\
Mother's education (y) & $\mathrm{r}=0.015, \mathrm{p}=0.830$ & $\mathrm{r}=0.019, \mathrm{p}=0.787$ \\
Household income (RM/month) & $\mathrm{r}=-0.048, \mathrm{p}=0.499$ & $\mathrm{r}=0.081, \mathrm{p}=0.255$ \\
Household size & $\mathrm{r}=-0.007, \mathrm{p}=0.916$ & $\mathrm{r}=-0.228, \mathrm{p}<0.01$ \\
Breast feeding duration (month) & $\mathrm{r}=0.189, \mathrm{p}<0.01$ & $\mathrm{r}=-0.081, \mathrm{p}=0.259$ \\
Weight-for-age, $\mathrm{z}$ score & $\mathrm{r}=0.151, \mathrm{p}<0.05$ & $\mathrm{r}=0.234, \mathrm{p}<0.01$ \\
Height-for-age, $\mathrm{z}$ score & $\mathrm{r}=0.004, \mathrm{p}=0.951$ & $\mathrm{r}=0.222, \mathrm{p}<0.01$ \\
BMI for age, $\mathrm{z}$ score & $\mathrm{r}=0.167, \mathrm{p}=\mathrm{p}<0.01$ & $\mathrm{R}=0.229, \mathrm{p}<0.01$ \\
\hline
\end{tabular}


Further analysis was done to determine the relationship between family and child characteristics with status of iron of the children by using t-test. Result indicated that there were significant differences in birth weight, household size and nutritional status of the children height for age, weight for age, BMI for age) between children with iron deficiency and children without iron deficiency (Table 5).

Table 5. Socio-demographic and anthropometric measurement between children with iron deficiency and children without iron deficiency

\begin{tabular}{cccc}
\hline Characteristics & \multicolumn{2}{c}{ Iron Status } & P- Value \\
& Iron Deficient & Normal & \\
\hline Age & $7.96 \pm 0.86$ & $8.08 \pm 0.88$ & 0.444 \\
Birth weight $(\mathrm{kg})$ & $2.86 \pm 0.42$ & $3.09 \pm 0.49$ & 0.007 \\
Years of fathers education & $8.66 \pm 2.96$ & $8.96 \pm 3.27$ & 0.607 \\
Years of mothers education & $9.55 \pm 2.41$ & $9.22 \pm 3.18$ & 0.545 \\
Household income & $926.25 \pm 799.19$ & $956.98 \pm 1159.28$ & 0.874 \\
Household size & $8.01 \pm 1.72$ & $6.82 \pm 1.88$ & 0.000 \\
Duration of reast feeding (months) & $18.88 \pm 9.14$ & $19.60 \pm 8.96$ & 0.646 \\
Weight for age, z score & $-1.44 \pm 1.05$ & $-0.81 \pm 1.36$ & 0.001 \\
Height for age, z score & $-1.36 \pm 0.98$ & $-0.98 \pm 0.84$ & 0.013 \\
BMI for age, z score & $-0.80 \pm 0.94$ & $-0.40 \pm 1.39$ & 0.033 \\
\hline
\end{tabular}

In the multivariate models, researchers included those demographic variables that were found significantly associated with the dependent variable in bivariate analyses. These variables included are age, gender, birth weight, household income, household size, duration of breast feeding, height for age-zscore, weight for age-zscore and BMI for age-zscore, Simple logistic regression was applied to determine the potential variables, which were of great values for the recurrence of ID. Variables having p-value of less than or equal to 0.25 were included to proceed for further multivariable analysis. Multiple logistic regression method was applied to determine the factors associated with the recurrence of ID.

Variable selection method with backward stepwise likelihood ratio option was applied. After that, preliminary main effect model was obtained. Interactions among independent variables 
were checked by creating clinically meaningful two-way interaction terms by using likelihood ratio test. Multi co-linearity was checked by observing correlation coefficients produced by co-linearity matrix among independent variables as well as size of standard errors of each independent predictor variables. Preliminary final model was obtained at this stage. The model fitness was then checked by Hosmer-Lemenshow goodness-of-fit test, classification table and area under Receiver Operation Characteristic (ROC) curve. Final model was obtained at this stage. Final results were presented by using crude and adjusted odds ratio with 95\% CI and corresponding P-value.

Results in multiple logistic regressions demonstrated that ID is associated with birth weight (odds ratio $[\mathrm{OR}]=0.023,95 \% \mathrm{CI}, 0.151,0.872, \mathrm{p}=0.023$ ) and household size (odds ratio $[\mathrm{OR}]=1.435,95 \% \mathrm{CI}, 1.164,1.768, \mathrm{p}=0.001)$, while other variables such as height for age-zscore, weight for age-zscore and BMI for age-zscore were not significantly related (Table 6). These results confirmed those previously shown (Table 3) that iron deficiency correlated significantly with household size and birth weight. Better iron status was associated with lower household size and higher birth weight. In [28] showed that family size was associated with a higher risk of low iron levels. Study by [29] also showed higher prevalence of iron deficiency anemia was also associated with larger family size ( $>6$ member).

Table 6. Multiple logistic regression analysis of factors associated with iron deficiency with or without anaemia

\begin{tabular}{cccccc}
\hline Variables & B & SE & OR & 95\% CIs & P-Value \\
\hline Birth weight & -1.013 & 0.447 & 0.363 & $(0.151,0.872)$ & 0.023 \\
Household size & 0.361 & 0.107 & 1.435 & $(1.164,1.768)$ & 0.001 \\
Height for age, z score & 0.028 & 0.304 & 1.029 & $(0.567,1.869)$ & 0.926 \\
Weight for age, z score & -0.422 & 0.294 & 0.655 & $(0.369,1.166)$ & 0.15 \\
BMI for age, z score & 0.129 & 0.232 & 1.138 & $(0.722,1.792)$ & 0.578 \\
\hline
\end{tabular}

Other studies reported that mothers' educational level plays an important role in the iron status of school children [28]. However, the present study found no significant correlation between mothers' education and prevalence of ID in children. This may be due to the small 
variation in the mothers' educational levels in our sample. This result is in agreement with other study where no significant correlation was also found between mother's education and status of iron [29]. It was also stated in other study that as the number of persons living in a house increase, their standard of living will be affected thus their expenditures will increase and share of food in expenditure will ultimately decrease which finally causes food insecurity [30]. Birth weight was also found to be one of the risk factors to develop iron deficiency among children [29].

Other than low socioeconomic and nutritional status of children, poor dietary intake was also found to be the main contributing factor in the higher iron deficiency anemia rates in young children from low-income households [31]. The total amount of iron in the body is determined by its iron intake, absorption, loss and storage. In children, risk factors for iron deficiency include diet poor in iron, poor in iron enhancers and diet rich in iron inhibitors such as polyphenols (certain vegetables), tannins (in tea), phytates (in bran) and calcium (in dairy products). However, dietary intake was not documented in our study and it needs to be further investigated. Other contributing factor is due to helminthic infection where it often reported among aboriginal children and children living in oil palm plantations as a result of poor hygiene and sanitary practices [16].

The present study has several limitations. Firstly, finding in this study was a cross sectional study therefore direct casual association between ID and its determinants could not be identified. Moreover, a result on iron status was depended solely on serum ferritin as the indicator. Although serum ferritin is well known for its stable biomarker for iron status, serum ferritin tends to be elevated during the presence of acute or chronic inflammation due to infections [32]. However, present study had screened and excluded those who had positive result and confirmed to have STH infection and thalassemia trait. Though, it is suggested to include other indicators such as C-reactive protein to indicate whether a normal or high level of ferritin is representing adequate of iron store for future study.

\section{EXPERIMENTAL}

\subsection{Study Area and Subjects}


This cross-sectional study was conducted in six primary schools selected randomly from a list of schools in Bachok's district, Kelantan where most of the residents are Malays and worked as a farmer and labourers. Data were collected between May and September 2009. School children aged 7-9 years comprising 127 males and 135 females were participated in this study. All the subjects were selected using systematic sampling from the school registry. Ethical approval was granted by the Human Ethics Committee of Universiti Sains Malaysia. Permission to conduct the research in the selected schools was obtained from the Ministry of Education, Malaysia and Kelantan State Education Department. A letter with a clear explanation about the objectives and research protocols was given to the parents of the children through the class teachers. Written consent and assent form were obtained from both the parents and the children before commencement of the research.

\subsection{Structured Questionnaire}

Questionnaires on demographic and socioeconomic data were completed by the parents. The information gathered included age, gender, ethnic group, number of children and birth order of the child understudy, parent's education level, occupation and household income. Information for birth weight was also included in the questionnaire.

\subsection{Anthropometric Measurements}

Measurement of body weight and height were performed according to standard procedures. Body weight was measured by weighing the children with school uniforms, without belt, shoes and socks by using digital scale (TANITA Corporation, Japan) with an accuracy of 0.1 kg. Height was measured using a microtoise tape (Secabodymeter 208, Hamburg Jermany) to the nearest $0.1 \mathrm{~cm}$. Anthropometric measurement were taken twice. Third measurement was taken whenever there are any discrepancies for the first two measurements. Mean average values were used for the final analysis. Mean z score were calculated and nutritional status was classified based on WHO 2007 references [3].

\subsection{Iron Status Determination}

Blood specimen was taken at the school by the doctors and nurses. About $2.5 \mathrm{ml}$ of blood was collected into each tube, $1.5 \mathrm{~mL}$ of the blood was placed into EDTA (ethylene-diamine-tetra-acetate) tube for the analysis of full blood count and screening of 
thalassemia and the remaining $1 \mathrm{~mL}$ was collected into micro-centrifuge tube (plain tube) for the estimation of serum ferritin.

Hemoglobin and red cell indices were analyzed using hematology analyzer Sysmex XE-2100 (Sysmex Corporation, Kobe, Japan). Sample of serum was used to determine blood ferritin by using the AxSYM Ferritin based on a microparticle enzyme immunoassay (MEIA) procedure (MEIA: AxSYM System, Abbot Diagnostic, US). Children were classified as iron deficient based on serum ferritin value of $<15 \mu \mathrm{g} / \mathrm{L}$ and categorized as anemic if the hemoglobin concentration value of $<11.5 \mathrm{~g} / \mathrm{dL}[19]$.

\subsection{Statistical Analysis}

All the statistical analysis was performed by using the program Statistical Package for Social Sciences (SPSS) version 12. Distribution of the data was assessed by descriptive analysis and all variables were tested for normality before any statistical analyses were made. The results are presented either as means and standard deviations (SD) or as proportions (\%). The results are presented as the mean and standard deviation (SD) or proportion (\%). The Pearson correlation coefficient test was used to determine the relationship between socio-demographic and anthropometric variables with iron status. P-value of $<0.05$ was considered as statistically significant. One-way ANOVA test was performed to assess if there is any differences for socio-demographic and anthropometric variables between children with iron deficient and children with normal iron status. A multiple linear regression analysis was done to determine the associated factors for iron deficiency.

\section{CONCLUSION}

In summary, our findings show a high prevalence of iron deficiency. Family and child characteristics such as household size and birth weight were found to be associated significantly with the prevalence of iron. The problem of ID with or without anemia not only has physiological consequences to humans, but it also has serious implications for economic, social and cognitive development among school children. As IDA is a common treatable condition therefore it is important for the health personnel particularly those working in primary health clinics to determine and treat IDA. This is to avoid its further consequences on 
cognitive abilities among the school children as well as to improve the quality of life in this group of population.

\section{ACKNOWLEDGEMENTS}

This study was supported by a research grant from the University Sains Malaysia (USM Research University Grant 1001/ppsk/812022). Authors would also like to thank the Ministry of Education, Kelantan's Department of Education and all the school involved in this study. Sincere gratitude is also expressed to all the subjects and their parents for their full support during the study.

\section{REFERENCES}

[1] Siti N A S, Wan M W M, Narazah M Y, Quah B S. Prevalence and risk factors for iron deficiency in Kelantanese pre-school children. Singapore Medical Journal, 2006, 47(11):935-939

[2] World Health Organization (WHO). The world health report 2002: Reducing risk, promoting healthy life. WHO: Geneva, 2002

[3] World Health Organization (WHO). Assessing the iron status of populations. WHO: Geneva, 2007

[4] Halterman J S, Kaczorowski J M, Aligne C A, Auinger P, Szilagyi P G. Iron deficiency and cognitive achievement among school aged children and adolescents in the United States. Pediatrics, 2001, 107(6):1381-1386

[5] Lozoff B, Jimanez E, Hagen J, Mollen E, Wolf A. W. Poor behavioural and development outcome more than 10 years after treatment for iron deficiency in infancy. Pediatrics, 2000, 105(4):1-11

[6] Beard J L. Iron biology in immune function, muscle metabolism and neuronal functioning. Journal of Nutrition, 2001, 131(2):5658-5805

[7] Levy A, Fraser D, Katz M, Mazor M, Sheiner E. Maternal anemia during pregnancy is an independent risk factor for low birthweight and preterm delivery. European Journal of Obstetrics and Gynecology and Reproductive Biology, 2005, 122(2):182-186 
[8] Lieu P T, Heiskala M, Peterson P A, Yang Y. The roles of iron in health and disease. Molecular Aspects of Medicine, 2001, 22(1):1-87

[9] Allen L H. Fourth report on the world nutrition situation. Geneva: ACC/SCN in collaboration with IFPRI, 2000

[10] Haas J D, Brownlie T. Iron deficiency and reduced work capacity: A critical review of the research to determine a causal relationship. Journal of Nutrition, 2001, 131(2):676-690

[11] Ekwochi U, Odetunde O I, Maduka I C, Azubuike J C, Obi I E. Iron deficiency among non-anemic under-five children in Enugu, South-East, Nigeria. Annals of Medical and Health Sciences Research, 2013, 3(3):402-406

[12] Bodnar L M, Cogswell M E, Scanlon K S. Low income postpartum women are at risk of iron deficiency. Journal of Nutrition, 2002, 132(8):2298-2302

[13] Tee Jr E S, Khor G L, Tony N, Yassin Z, Chee H, Mdyusof S. Nutritional assessment of rural villages and estates in Peninsular Malaysia. III. Prevalence of anaemia. Malaysian Journal of Nutrition, 1998, 4(1):1-29

[14] Hamid J J M, Mitra A K, Rohani A, Norimah A K. Association of iron deficiency with or without anaemia and cognitive functions among primary school children in Malaysia. Malaysian Journal of Nutrition, 2010, 16(2):261-270

[15] Foo L H, Khor G L, Tee E, Prabakaran D. Iron status and dietry iron intake of adolescents from a rural community in Sabah, Malaysia. Asia Pacific Journal of Clinical Nutrition, 2004, 13(1):48-55

[16] Al-Mekhlafi M H, Surin J, Atiya A S, Ariffin W A, Mahdy A M, Abdullah H C. Anaemia and iron deficiency anaemia among aboriginal schoolchildren in rural Peninsular Malaysia: An update on a continuing problem. Transactions of the Royal Society of Tropical Medicine and Hygiene, 2008, 102(10):1046-1052

[17] Ngui R, Lim Y A, Kin L C, Chuen C S, Jaffar S. Association between anaemia, iron deficiency anaemia, neglected parasitic infections and socioeconomic factors in rural children of West Malaysia. PLoS Neglected Tropical Diseases, 2012, 6(3):1-8

[18] Sharma B, Mitra M, Chakrabarty S, Bharati P. Nutritional status of preschool children of Raj Gond-A tribal population in Madhya Pradesh, India. Malaysian Journal of Nutrition, 2006, 


\section{2(2):147-155}

[19] World Health Organization (WHO). Iron deficiency anaemia: Assessment, prevention, and control-A guide for programme managers. Geneva: WHO, 2001

[20] Brooker S, Jardim-Botelho A, Quinnell R J, Geiger S M, Caldas I R, Fleming F, Hotez P J, Correa-Oliveira R, Rodrigues L C, Bethony J M. Age-related changes in hookworm infection, anaemia and iron deficiency in an area of high Necatoramericanus hookworm transmission in south-eastern Brazil. Transactions of the Royal Society of Tropical Medicine and Hygiene, 2008, 101(2):146-154

[21] Jinabhai C C, Taylor M, Coutsoudis A, Coovadia H M, Tomkins A M, Sullivan K R. A health and nutritional profile of rural school children in Kwazulu Natal, South Africa. Annals of Tropical Paediatrics, 2001, 21(1):50-56

[22] Aini U N, Al-Mekhlafi M H, Azlin M, Shaik A, Sa A, Fatmah M S, Ismail M G, Firdaus M A, Aisah M Y, Rozlida A R, Norhayati M. Serum iron status in Orang Asli children living in endemic areas of soil-transmitted helminthes. Asia Pacific Journal of Clinical Nutrition, 2007, 16(4):724-730

[23] Abbaspour N, Hurrell R, Kelishadi R. Review on iron and its importance for human health. Journal of Research in Medical Sciences, 2014, 19(2):164-174

[24] Sungthong R, Mo-suwan L, Chongsuvivatwong V. Effects of haemoglobin and serum ferritin on cognitive function in school children. Asia Pacific Journal of Clinical Nutrition, 2002, 11(2):117-122

[25] Loh S P, Khor G L. Iron intake and iron deficiency anaemia among young women in Kuala Lumpur. Malaysian Journal of Medicine and Health Sciences, 2010, 6(1):63-70

[26] Rushton D H, Dover R, Sainsbury A W, Norris M J, Gilkes J J, Ramsay I D. Why should women have lower reference limits for hemoglobin and ferritin concentrations than men? British Medical Journal, 2001, 322(7298):1355-1357

[27] Milman N, Clausen J, Byg K E. Iron status in 268 Danish women aged 18-30 years: Influence of menstruation, contraceptive method, and iron supplementation. Annals of Hematology, 1998, 77(1):13-19

[28] Liu J, Ai Y X, Hanlon A, Shi Z, Dickerman B, Compher C. Micronutrients deficiency 
and associated socio-demographic factors in Chinese children. World Journal of Pediatrics, 2011, 7(3):217-223

[29] Kounnavong S, Sunahara T, Hashizume M, Okumura J, Moji K, Boupha B, Yamamoto T. Anemia and related factors in preschool children in the Southern Rural Lao People's Democratic Republic. Tropical Medicine and Health, 2001, 39(4):95-103

[30] Aslam M, Rasool S. Investigating the impact of major variables influencing food security in Lahore, Pakistan. International Journal on Advanced Science, Engineering and Information Technology, 2014, 4(3):143-147

[31] Khor G L. Micronutrient status and intervention programs in Malaysia. Food and Nutrition Bulletin, 2005, 26(2):281-285

\section{How to cite this article:}

Halib H, Wan Muda WM, Dam PC, Mohamed HJJ. Prevalence of Iron Deficiency and Its Associated Risk Factors Among Primary School Children In Kelantan. J. Fundam. Appl. Sci., 2017, 9(2S), 397-412. 